\title{
PENGARUH PELATIHAN DAN MOTIVASI TERHADAP KINERJA KARYAWAN DENGAN PRODUKTIVITAS KERJA SEBAGAI VARIABEL INTERVENING PADA BANK UMUM SYARIAH DI KOTA PALEMBANG
}

\author{
Muhammad Ilham Qolbi, Maya Panorama dan Peny Cahaya Azwari \\ Universitas Islam Negeri (UIN) Raden Fatah Palembang, Indonesia \\ Email: aamqolbi@gmail.com,maya.izuddin@gmail.com dan \\ penycahayaazwari_uin@radenfatah.ac.id
}

\section{Abstract}

This study aims to determine the effect of training and motivation on employee performance through work productivity as the intervening variable on the employees of shariah commercial banks in Palembang. In this study data were collected by distributing questionnaires to 80 employees as respondents at shariah commercial banks in the city of Palembang. Using purposive sampling method to determine respondents' responses to the research variables. The analysis was performed using the method of partial least square (PLS). The results of the analysis show that the variables of training, motivation and work productivity have a positive and significant effect on employee performance, and motivation on work productivity has a positive and significant effect, while training has no effect on work productivity. And work productivity variable is able to mediate the influence of motivation on employee performance. As for the work productivity, this variable is not able to mediate the effect of training variable on employee performance.

Keywords: training; motivation; performance; work productivity

\section{Abstrak}

Penelitian ini bertujuan untuk mengetahui seberapa besar Pengaruh Pelatihan dan Motivasi Terhadap Kinerja Karyawan Dengan Produktivitas Kerja Sebagai Variabel Intervening Pada Bank Umum Syariah di Kota Palembang. Dalam penelitian ini data dikumpulkan dengan meyebarkan kuesioner terhadap 80 responden karyawan pada bank umum syariah di kota Palembang. menggunakan metode purposive sampling untuk mengetahui tanggapan responden terhadap variabel yang ada. Analisis dilakukan dengan menggunakan metode partial least square (PLS). Hasil analisis menunjukkan bahwa variabel pelatihan, motivasi dan produktivitas kerja berpengaruh positif dan signifikan terhadap kinerja karyawa, dan motivasi terhadap produktivitas kerja berpengaruh positif dan signifikan, Sedangkan pelatihan tidak berpengaruh terhadap produktivitas kerja karyawan pada bank umum syariah di Kota Palembang. Dan variabel produktivitas mampu memediasi pengaruh motivasi terhadap kinerja karyawan. Sedangkan pengaruh variabel pelatihan terhadap kinerja karyawan tidak dapat dimediasi oleh variabel produktivitas kerja. 
Kata Kunci: pelatihan; motivasi; kinerja; produkivitas kerja

\section{Pendahuluan}

Bank Umum Syariah di Palembang telah mengalami perkembangan yang cukup pesat namun masih menghadapi permasalahan terkait dengan kinerja karyawan pada perusahaan tersebut. Perusahaan selalu mengharapkan kinerja karyawannya dapat meningkat dengan baik.

Untuk meningkatkan kinerja karyawan, maka dibentuk pelatihan teknis dan manajerial kepada seluruh karyawan sehingga terbentuklah pelatihan yang bermanfaat dan berdaya guna selain itu mampu meghasilkan karyawan yang terampil dan berkualitas. Berikut ini tabel kinerja Bank Umum Syariah Tahun 2016 - 2019.

\section{Tabel 1}

Kinerja Bank Umum Syariah

Tahun 2016-2019 Dari Total Aset

\begin{tabular}{llllll}
\hline No & Bank Umum Syariah & $\mathbf{2 0 1 6}$ & $\mathbf{2 0 1 7}$ & $\mathbf{2 0 1 8}$ & $\mathbf{2 0 1 9}$ \\
\hline 1 & BCA Syariah & 4.995 & 5.961 & 7.064 & 8.064 \\
\hline 2 & BNI Syariah & 28.314 & 34.822 & 41.049 & 49.980 \\
\hline 3 & BRI Syariah & 27.687 & 31.543 & 37.915 & 43.123 \\
\hline 4 & Mandiri Syariah & 78.831 & 87.915 & 98.341 & 112.291 \\
\hline 5 & BTPN Syariah & 7.323 & 9.156 & 12.039 & 15.383 \\
\hline 6 & Bank Mega Syariah & 6.135 & 7.034 & 7.336 & 8.007 \\
\hline 7 & Bank Panin Dubai Syariah & 8.757 & 8.629 & 8.771 & 11.135 \\
\hline 8 & Bank Muamalat & 55.786 & 61.697 & 57.227 & 55.556 \\
\hline
\end{tabular}

Sumber: Annual Report 2016 - 2019

Berdasarkan tabel 1 terlihat tingkat realisasi pencapaian asset bank umum syariah dalam periode 4 tahun terakhir mengalami naik turun. Angka yang ditunjukkan berfluktuatif.

Tabel 2

Kinerja Bank Umum Syariah Tahun 2016-2019 Dari Laba Bersih

\begin{tabular}{llllll}
\hline No & Bank Umum Syariah & $\mathbf{2 0 1 6}$ & $\mathbf{2 0 1 7}$ & $\mathbf{2 0 1 8}$ & $\mathbf{2 0 1 9}$ \\
\hline 1 & BCA Syariah & 36.800 & 47.900 & 58.400 & 67.200 \\
\hline 2 & BNI Syariah & 277.000 & 307.000 & 416.000 & 603.000 \\
\hline 3 & BRI Syariah & 170.209 & 101.091 & 106.600 & 74.016 \\
\hline 4 & Mandiri Syariah & 325.414 & 365.166 & 605.213 & 1.275 .034 \\
\hline 5 & BTPN Syariah & 412.495 & 670.182 & 965.311 & 1.399 .634 \\
\hline 6 & Bank Mega Syariah & 110.729 & 72.555 & 46.577 & 49.151 \\
\hline 7 & Bank Panin Dubai Syariah & 19.540 & $(968)$ & 20.788 & 13.237 \\
\hline 8 & Bank Muamalat & 81.000 & 26.000 & 46.000 & 16.000 \\
\hline
\end{tabular}

Sumber: Annual Report 2016 - 2019

Berdasarkan Annual report tahun 2016-2019, kinerja bank umum syariah tahun 2016- 2019 dari total aset dan kinerja bank umum syariah tahun 2016-2019 dari laba bersih, realisasi pencapaian total aset dan laba bersih berfluktuatif. Hal ini dikarenakan 
Pengaruh Pelatihan dan Motivasi terhadap Kinerja Karyawan dengan Produktivitas

Kerja Sebagai Variabel Intervening pada Bank Umum Syariah Di Kota Palembang

Meningkatnya persaingan antar perbankan syariah sehingga perusahaan membutuhkan karyawan yang handal dan sigap. Untuk melihat lebih jauh fenomena tersebut, maka penelitian ini akan menggunakan teori Maslow dan teori maqashid syariah.

Teori Mashlow yang dikemukakan oleh Abraham Maslow adalah teori motivasi paling terkenal tentang hakekat manusia, bahwa manusia memiliki satu kesatuan jiwa dan raga yang bernilai baik, dan memiliki potensi-potensi. Ia membuat hipotesis bahwa dalam setiap diri manusia terdapat hierarki dari lima kebutuhan, diantaranya, fisiologis (physiological) yaitu kebutuhan dasar seperti: rasa lapar, haus, seksual, dan kebutuhan fisik lainnya. Kedua, rasa aman (safety and security). Rasa ingin dilindungi dari bahaya fisik dan emosional. Ketiga, rasa memiliki atau sosial (belongingness and love). Rasa kasih sayang, kepemilikan, penerimaan, dan persahabatan. Keempat, penghargaan (esteem). Faktor penghargaan internal dan eksternal. Kelima, aktualisasi diri (self actualizatin) pertumbuhan, pencapaian potensi seseorang, dan pemenuhan diri sendiri. Sedangkan teori maqashid syariah adalah untuk mewujudkan kebaikan sekaligus menghindarkan keburukan, atau menarik manfaat dan menolak madharat (maslahat).

Kinerja karyawan dapat dilihat dari tercapainya target kantor-kantor cabang yang telah ditetapakan oleh kantor pusat baik dari sisi penambahan asset maupun laba bersih. untuk meningkatkan kinerja karyawan dibutuhkan motivasi agar karyawan terus bersemangat dalam mencapai target yang telah ditetapkan oleh perusahaan. Sedangkan Pelatihan kerja bagi karyawan merupakan salah satu cara bagaimana karyawan bisa meningkatkan kinerja. Pelatihan dilaksanakan oleh perusahaan bertujuan untuk melatih kemampuan karyawan dan memberikan pengetahuan baru bagi karyawan.

Berdasarkan pengalaman penulis bekerja di Bank Umum Syariah, fenomena yang menyebabkan menurunnya kinerja karyawan adalah manajemen jarang melakukan komunikasi dua arah dengan karyawan untuk mendengarkan keluhan para karyawan. Pelatihan yang diberikan guna mendukung produktivitas kerja karyawan kurang efektif hal ini dikarenakan tidak adanya pengukuran baik sebelum maupun sesudah pelatihan sehingga produktivitas kerja yang dihasilkan karyawan tidak seperti yang diharapkan perusahaan.

Selain itu, beberapa karyawan merasa kurangnya motivasi dari pimpinan secara langsung. Karyawan sangat butuh motivasi dan hal-hal positif saat bekerja karena hal tersebut dapat menumbuhkan semangat dalam bekerja untuk pencapaian target perusahaan. Motivasi belum optimal bisa jadi menjadi penyebab belum tercapainya standar kinerja yang telah ditetapkan. Dalam penelitian-penelitian sebelumnya banyak menggunakan variabel motivasi mempengaruhi kinerja karyawan.

Berdasarkan data, fenomena yang tejadi dan adanya research gap antara penelitian sebelumnya pada latar belakang permasalahan diatas maka peneliti mengambil judul "Pengaruh Pelatihan dan Motivasi Terhadap Kinerja Karyawan Dengan Produktivitas Kerja Sebagai Variabel Intervening Pada Bank Umum Syariah di Kota Palembang”. 


\section{Metode Penelitian}

Metode analisis yang digunakan dalam penelitian inii yaitu analisis jalur (path analysis). Metode analisis ini dapat digunakan untuk mengetahui besarnya pengaruh pelatihan dan motivasi terhadap kinerja karyawan dengan produktivitas kerja sebagai variabel intervening pada bank umum syariah di Kota palembang. Data yang digunakan dalam penelitian ini adalah data primer dengan teknik pengumpulan data dilakukan dengan penyebaran kuesioner. Populasi penelitian adalah karyawan pada bank umum syariah di Kota palembang yang sesuai kriteria untuk dijadikan responden. Kriteria yang digunakan meliputi demografi, pelatihan, motivasi, kinerja karyawan, dan produktivitas kerja pada bank umum syariah di Kota Palembang. Penentuan jumlah sampel yang di tentukan berdasarkan perhitungan melalui rumus Hair et al adalah tergantung pada jumlah indikator dikali 5 sampai 10 (Hair, Black, Babin, Anderson, \& Tatham, 2006). Jumlah sampel dalam penelitian ini adalah 80 responden, Penelitian ini menggunakan teknik Stratified random sampling. Kuesioner tersebut didistribusikan pada 8 Bank Umum Syariah di kota Palembang, antara lain ialah pada Bank BCA Syariah, Bank Mandiri Syariah, Bank BNI Syariah, Bank BRI Syariah, BTPN Syariah, Bank Mega Syariah, Bank Panin Dubai Syariah dan Bank Muamalat berdasarkan kategori Pendidikan, Usia, Jabatan, dan Lama Bekerja. Kondisi ini dilakukan untuk memastikan bahwa responden cukup berpengetahuan untuk memahami kinerja karyawan pada bank umum syariah di kota palembang yang menempatkan masalah yang diteliti.

Pada penelitin ini analisis data yang digunakan adalah uji validitas, uji reliailitas dan uji hipotesis dengan SEM (structural Equation Modeling). Uji validitas dilakukan dengan melihat korelasi antara variabel satu dengan yang lain. Metode yang digunakan adalah uji validitas konvergen, dimana nilai loading factor dari setiap indicator pertanyaan harus lebih besar dari 0,50. Dengan begitu seluruh variabel teramati, yang dituangkan melalui setiap pertanyaan dalam kuesioner, dapat dengan tepat mengukur variabel latennya. Berdasarkan hasil perhitungan ini, maka variabel dalam kuesioner dianggap valid dan dapat digunakan untuk pengolahan data. Uji Reliabilitas dalam penelitian ini menggunkan metode Cronbach's Alpha yang dianggap reliable apabila memiliki nilai Cronbach'S alpha lebih dari 0.6 dan nilai composite reability lebih besar dari 0,6-0,7 untuk penelitian yang bersifat exploratory. Apabila seluruh variabel memiliki koefisien alpha dan composite reability lebih besar dari 0,6. Artinya kuesioner yang digunakan dalam penelitian ini dianggap reliable, karena menunjukan tingkat konsistensi dan keakuratan yang baik. Uji hipotesis dilakukan untuk mengetahui hubungan adanya pengaruh atau tidak antar variabel penelitian dengan metode resampling bootstrap yang dikembangkan oleh geisser. Pengujian hipotesis menggunakan analisis full model Struktural Equation Modeling (SEM) dengan smartPLS. Dalam full model SEM dengan smartPLS selain memprediksi model, juga menjelaskan ada atau tidaknya hubungan antar variabel laten. Hipotesis penelitian diterima jika nilai weight dari hubungan antar variabel laten menunjukkan arah dengan nilai t-statistik di atas nilai t-tabel 1,96 
Pengaruh Pelatihan dan Motivasi terhadap Kinerja Karyawan dengan Produktivitas

Kerja Sebagai Variabel Intervening pada Bank Umum Syariah Di Kota Palembang

untuk $\alpha=0,5$ : Hipotesis penelitian ditolak jika nilai weight dari hubungan antar variabel menunjukkan nilai t-statistik dibawah nilai t- tabel untuk $\alpha=0,5$.

\section{Hasil dan Pembahasan}

\section{A. Hasil}

1. Pengujian Model Pengukuran (Measurement Model)

\section{a. Outer Loading Factor}

Nilai loading factor sebesar 0,50 atau lebih dianggap memiliki validasi yang cukup kuat untuk menjelaskan konstruk laten. Nilai outer loading awal pada variabel pelatihan, motivasi, kinerja karyawan dan produktivitas kerja dapat dilihat pada Tabel berikut Menurut (Yamin \& Kurniawan, 2011) indikator yang memiliki nilai loading factor antara 0.5 0.6 dapat diterima.

\section{Tabel 3}

Outer Loading

\begin{tabular}{|c|c|c|c|c|}
\hline & $\begin{array}{c}\text { Kinerja } \\
\text { Karyawan Y }\end{array}$ & $\begin{array}{l}\text { Motivasi } \\
\text { X2 }\end{array}$ & $\begin{array}{l}\text { Pelatihan } \\
\text { X1 }\end{array}$ & $\begin{array}{c}\text { Produktivitas Kerja } \\
\mathrm{Z} \\
\end{array}$ \\
\hline KK1 & 0.665 & & 0.953 & \\
\hline KK10 & 0.852 & & 0.955 & \\
\hline KK3 & 0.747 & & & \\
\hline KK4 & 0.826 & & & \\
\hline KK5 & 0.860 & & & \\
\hline KK6 & 0.884 & & & \\
\hline KK7 & 0.862 & & & \\
\hline KK8 & 0.737 & & & \\
\hline MTV1 & & 0.853 & & \\
\hline MTV2 & & 0.832 & & \\
\hline MTV3 & & 0.836 & & \\
\hline MTV4 & & 0.896 & & \\
\hline MTV5 & & 0.860 & & \\
\hline MTV6 & & 0.752 & & \\
\hline PEL1 & & & 0.817 & \\
\hline PEL3 & & & 0.708 & \\
\hline PEL5 & & & 0.834 & \\
\hline PEL6 & & & 0.846 & \\
\hline PEL7 & & & 0.864 & \\
\hline PEL8 & & & 0.881 & \\
\hline PEL9 & & & 0.879 & \\
\hline PK1 & & & & 0.775 \\
\hline PK2 & & & & 0.804 \\
\hline PK3 & & & & 0.879 \\
\hline PK4 & & & & 0.841 \\
\hline PK5 & & & & 0.805 \\
\hline PK6 & & & & 0.843 \\
\hline
\end{tabular}

Sumber: Hasil penelitian diolah dengan smartPLS 3.0, 2021 
Indikator yang dieliminasi pada model ini ada 5 yaitu PEL2 $=0,394$, PEL10 $=0.467$, PEL4 $=0,432$, KK2 $=0,441$ dan KK9 $=0.431$ kedua indicator ini memiliki nilai loading faktor dibawah 0,50. Setelah menghilangkan indicator variabel yang tidak valid dalam model, selanjutnya model kembali dicalculate sehingga menghasilkan nilai outer loading yang baru dan dapat dilihat pada gambar path diagram final berkut ini:

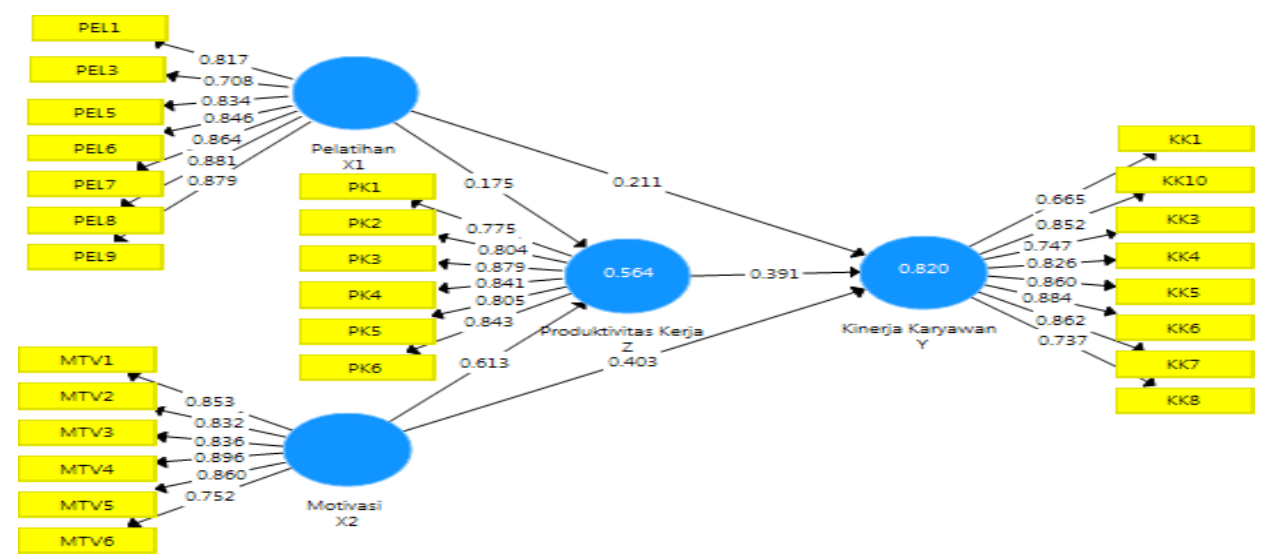

\section{Gambar 1 \\ Path Diagram Final}

Sumber: Hasil penelitian diolah dengan smartPLS 3.0, 2021

Dari total indikator awal pengoprasian 32 tersisa 25 untuk dilakukan pengujian lebih lanjut. Ada 5 indikator yang dihilangkan atau di eliminasi dari model.

\section{b. Uji Reliabilitas}

Instrument reliabilitas dalam penelitian ini diukur dengan dua Kriteria yaitu nilai composite reliability dan cronbach's alpha. Penggunaan cronbach's alpha cendrung menaksirkan lebih renda reliabilitas variabel dibandingkan composite reliability sehingga disarankan untuk menggunakan composite reliability menurut (Haryono, 2017). Sebuah konstruk dapat dikatakan reliable apabila nilai cronbach's alpha lebih 0,70 sedangkan menurut (Belisle, Gautier, Ghozali, Plantier, \& Wechsler, 2005) variabel dikatakan reliabel jika nilai composite reliability di atas 0,70 . 
Pengaruh Pelatihan dan Motivasi terhadap Kinerja Karyawan dengan Produktivitas Kerja Sebagai Variabel Intervening pada Bank Umum Syariah Di Kota Palembang

\section{Tabel 4}

Construct reliability dan validity

\begin{tabular}{lcccc}
\hline & $\begin{array}{c}\text { Cronbach's } \\
\text { Alpha }\end{array}$ & rho_A & $\begin{array}{c}\text { Composite } \\
\text { Reliability }\end{array}$ & $\begin{array}{c}\text { Average Variance } \\
\text { Extracted }(\boldsymbol{A V E})\end{array}$ \\
\hline $\begin{array}{l}\text { Kinerja Karyawan } \\
\text { Y }\end{array}$ & 0.922 & 0.927 & 0.937 & 0.652 \\
\hline Motivasi X2 & 0.915 & 0.917 & 0.934 & 0.704 \\
\hline Pelatihan X1 & 0.926 & 0.931 & 0.941 & 0.696 \\
\hline $\begin{array}{l}\text { Produktivitas Kerja } \\
\text { Z }\end{array}$ & 0.906 & 0.911 & 0.927 & 0.681 \\
\hline
\end{tabular}

Sumber: Hasil penelitian diolah dengan smartPLS 3.0, 2021

Berdasarkan tabel Construct reliability dan validity menunjukan bahwa semua variabel penelitian memiliki nilai cronbach's alpha dan composite reliability di atas 0,70. Oleh karena itu indicator yang digunakan dalam variabel penelitian ini dikatakan reliable. Sedangkan validitas mengunakan nilai average variance axtracted (AVE) dengan nilai batasan diatas 0,50 pada tabel IV.13 terlihat bahwa semua variabel memiliki nilai AVE diatas 0,50. Hal ini dapat diartikan bahwa keseluruhan indikator dan variabel dinyatakan valid.

\section{c. Uji Korelasi Diskriminan}

Uji korelasi diskriminan dilakukan untuk melihat korelasi antara konstruk dengan konstruk lainya. Jika nilai akar kuadrad (square root of average) AVE setiap konstruk lebih besar daripada nilai korelasi antara konstruk dengan konsturk lainya dalam model maka dapat disimpulkan bahwa konstruk memiliki tingkat validitas yang baik.

Tabel 5

Nilai Discriminant Validity

\begin{tabular}{lcccc}
\hline & $\begin{array}{c}\text { Kinerja } \\
\text { KaryawanY }\end{array}$ & $\begin{array}{c}\text { Motivasi } \\
\text { X2 }\end{array}$ & $\begin{array}{c}\text { Pelatihan } \\
\text { X1 }\end{array}$ & $\begin{array}{c}\text { Produktivitas } \\
\text { KerjaZ }\end{array}$ \\
\hline $\begin{array}{l}\text { Kinerja } \\
\text { Karyawan Y }\end{array}$ & 0.808 & & & \\
\hline Motivasi X2 & 0.847 & 1.839 & & \\
\hline Pelatihan X1 & 0.749 & 0.749 & 0.835 & \\
\hline $\begin{array}{l}\text { Produk } \\
\text { tivitas }\end{array}$ & 0.821 & 0.741 & 0.623 & 0.825 \\
KerjaZ & & & & \\
\hline
\end{tabular}

Sumber: Hasil penelitian diolah dengan smartPLS 3.0, 2021

Pada tabel nilai discriminant validity perbandingan nilai akar AVE memperlihatkan bahwa masing-masing dari nilai tersebut lebih besar dibandingkan dengan korelasi antar variabel lainya, sehingga dapat ditarik kesimpulan bahwa semua variabel laten dalam penelitian memiliki construct validity dan discriminant validity yang baik. 


\section{Pengujian Structural Model}

Pengujian structural model dilakukan untuk melihat hubungan antara konstruk, nilai signifikansi dan $R$-square dari model penelitian. Nilai $R$ square dapat digunakan untuk menilai pengaruh variabel independen tertentu terhadap variabel dependen. Nilai estimasi $R$ - square dapat dilihat pada Tabel berikut ini.

\section{Tabel 6}

Nilai $R$-square

\begin{tabular}{ccc}
\hline & $\boldsymbol{R}$-square & Adjusted $\boldsymbol{R}$-square \\
\hline Kinerja Karyawan & 0.820 & 0.813 \\
\hline Produktivitas Kerja & 0.664 & 0.653 \\
\hline
\end{tabular}

Sumber: Hasil penelitian diolah dengan smartPLS 3.0, 2021

Berdasarkan tabel 6 diketahui bahwa Nilai $R$-square untuk variabel kinerja karyawan sebesar 0,820 atau $82 \%$ dan variabel Produktivitas Kerja sebesar 0.664 atau $66,4 \%$ yang dapat di interprestasikan bahwa besarnya faktor yang mempengaruhi kinerja karyawan bank umum syariah di kota Palembang dapat dijelaskan oleh faktor pelatihan dan motivasi sedangkan sebesar $18 \%$ dipengaruhi oleh variabel lain diluar penelitian ini.

\section{Evaluasi Fit Test of Combination Model (Seluruh Model)}

Pada PLS Path Modelling dapat mengidentifikasi kriteria global optimization untuk mengetahui goodness of fit index. Goodness of fit atau GoF Index dikembangkan oleh (Tenenhaus, 2004) digunakan untuk mengevaluasi model pengukuran dan model structural dan disamping itu menyediakan pengukuran sederhana untuk keseluruhan dari prediksi model. kriteria nilai GoF adalah 0,10, 0,025 dan 0,36 yang menunjukan bahwa GoF small, GoF Medium dan GoF Large (Ghozali \& Latan, 2015). Nilai GoF dapat dinilai pada tabel berikut ini.

Tabel 7

Goodness of Fit

\begin{tabular}{ccc}
\hline Item & R-square & Communality \\
\hline Kinerja Karyawan & 0.820 & 0.836 \\
\hline Produktivitas Kerja & 0.664 & 0.675 \\
\hline Mean & 0.742 & 0.756 \\
\hline GoF & & 0.645
\end{tabular}

Sumber: Hasil penelitian diolah dengan smartPLS 3.0, 2021

Nilai GoF dihitung dengan akar kuadrat nilai average communality index dan averageR-squares (Tenenhaus, 2004) dalam (Ghozali \& Latan, 2015).

$$
\begin{aligned}
\mathrm{GoF} & =\sqrt{\operatorname{com} \times R^{2}} \\
& =\sqrt{0.756 \times 0.742} \\
& =0.645
\end{aligned}
$$


Pengaruh Pelatihan dan Motivasi terhadap Kinerja Karyawan dengan Produktivitas Kerja Sebagai Variabel Intervening pada Bank Umum Syariah Di Kota Palembang

Berdasarkan tabel Goodness of fit dan perhitungan rumus diatas menunjukan bahwa nilai GoF sebesar 0.645 dengan demikian model termasuk kedalam kriteria Large.

Pengujian hipotesis dengan menggunakan fungsi Bootstripping pada SmartPLS 3.0. hipotesis diterima pada saat tingkat signifikan lebih kecil dari 0,05 atau t-value melebihi nilai kritisnya. Nilai t statistics untuk tingkat signifikansi 5\% sebesar 1,96. Dapat dilihat pada gambar path diagram serta tabel Hasil Path Coefficient berkut ini:

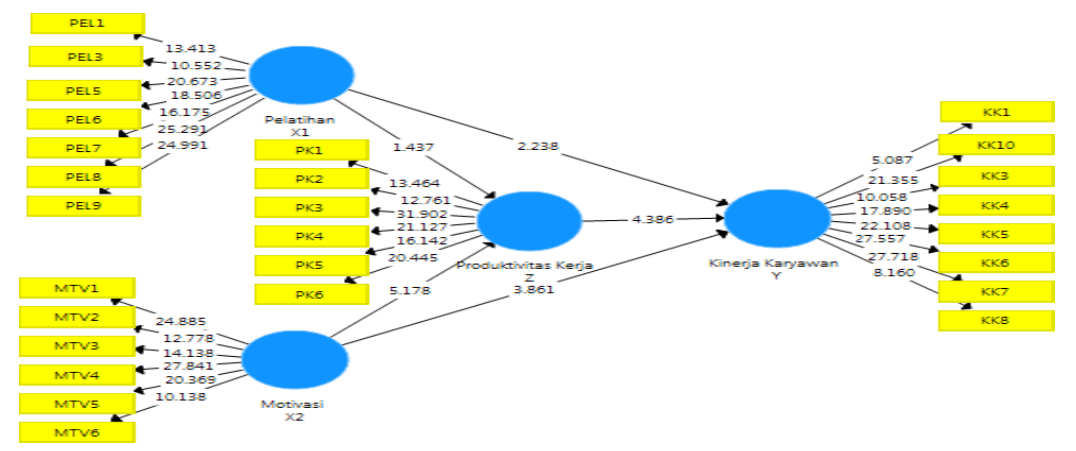

Gambar 2 Path Diagram

Sumber: Hasil penelitian diolah dengan smartPLS 3.0, 2021

Tabel 8

Uji Hipotesis Hasil Path Coefficient

\begin{tabular}{|c|c|c|c|c|c|c|c|}
\hline & $\begin{array}{c}\text { Variabel/Konstru } \\
\mathbf{k}\end{array}$ & $\begin{array}{c}\text { Origi } \\
\text { nal } \\
\text { Sam } \\
\text { pel }\end{array}$ & $\begin{array}{c}\text { Sam } \\
\text { pel } \\
\text { Me } \\
\text { an }\end{array}$ & $\begin{array}{c}\text { Standa } \\
\text { rd } \\
\text { Devia } \\
\text { tion } \\
\text { (STD } \\
\text { EV) }\end{array}$ & $\begin{array}{c}\mathbf{T} \\
\text { Statisti } \\
\mathbf{k} \\
(\mathbf{O} / \mathbf{S T} \\
\text { DEV) }\end{array}$ & $\begin{array}{l}\text { P } \\
\text { Val } \\
\text { ues }\end{array}$ & Hasil \\
\hline H1 & $\begin{array}{l}\text { Pelatihan } \square \\
\text { Produktivitas } \\
\text { Kerja }\end{array}$ & 0.175 & 0.193 & 0.122 & 1.437 & 0.151 & Ditolak \\
\hline$\overline{\mathrm{H} 2}$ & $\begin{array}{l}\text { Pelatihan } \square \\
\text { Kinerja } \\
\text { Karyawan }\end{array}$ & 0.211 & 0.211 & 0.094 & 2.238 & 0.026 & Diterima \\
\hline $\mathrm{H} 3$ & $\begin{array}{l}\text { Produktivitas Kerja } \\
\square \\
\text { Kinerja Karyawan }\end{array}$ & 0.391 & 0.388 & 0.089 & 4.386 & 0.000 & Diterima \\
\hline $\mathrm{H} 4$ & $\begin{array}{l}\text { Motivasi } \\
\text { Kinerja } \\
\text { Karyawan }\end{array}$ & 0.403 & 0.404 & 0.104 & 3.861 & 0.000 & Diterima \\
\hline H5 & $\begin{array}{l}\text { Motivasi } \square \\
\text { Produktivitas } \\
\text { Kerja }\end{array}$ & 0.613 & 0.601 & 0.118 & 5.178 & 0.000 & Diterima \\
\hline
\end{tabular}

Sumber: Hasil penelitian diolah dengan smartPLS 3.0, 2021 
Tabel 9

Uji Hipotesis Hasil indirect Effect

\begin{tabular}{llcccccc}
\hline Variabel/Konstruk & $\begin{array}{c}\text { Original } \\
\text { Sampel }\end{array}$ & $\begin{array}{c}\text { Sampel } \\
\text { Mean }\end{array}$ & $\begin{array}{c}\text { Standard } \\
\text { Deviation } \\
\text { (STDEV) }\end{array}$ & $\begin{array}{c}\text { T Statistik } \\
\text { (O/STDEV) }\end{array}$ & P Values & Hasil \\
\hline H6 & $\begin{array}{l}\text { Pelatihan } \square \text { Produktivitas Kerja } \\
\quad\end{array}$ & 0.069 & 0.074 & 0.048 & 1.420 & 0.156 & Ditolak \\
$\quad \begin{array}{l}\text { Kinerja Karyawan } \\
\text { H7 }\end{array}$ & $\begin{array}{l}\text { Motivasi } \square \text { Produktivitas Kerja } \\
\text { Kinerja }\end{array}$ & 0.240 & 0.234 & 0.072 & 3.336 & 0.001 & Diterima \\
$\quad$ Karyawan & & & & & \\
\hline
\end{tabular}

Sumber: Hasil penelitian diolah dengan smartPLS 3.0, 2021

Dari hasil path coefficient dan indirect Effect di atas dapat dilihat nilai $\mathrm{p}$ value atau $\mathrm{t}$ statistics yang digunakan sebagai acuan untuk mengambil keputusan hipotesis diterima atau hipotesis ditolak. Hipotesis dapat diterima jika nilai $\mathrm{t}$ statistics $>\mathrm{t}$ tabel $>1,96$ atau $\mathrm{p}$ value $<0,05$.

\section{B. Pembahasan}

H1: Pelatihan Tidak Berpegaruh Terhadap Produktivitas Kerja Pada Bank Umum Syariah di Kota Palembang Hasil penelitian ini sejalan dengan penelitian (Sambur, Mananeke, \& Taroreh, 2018). Pelatihan merupakan Pembelajaran para karyawan tentang kompetensi-kompetensi yang berkaitan dengan pekerjaan. Kompetensi tersebut meliputi pengetahuan, keterampilan, dan perilaku-perilaku yang sangat penting atau berpengaruh langsung terhadap kinerja karyawan dan meningkatkan produktivitas karyawan dengan ini dapat mewujudkan tujuan suatu perusahaan atau pemenuhan standar sumber daya manusia yang diinginkan. Peneliti mengindikasi faktor penyebab pelatihan tidak dapat mempengaruhi produktivitas kerja ialah kurang tepatnya sasaran kepada siapa pelatihan akan di berikan dan tidak ada evaluasi setelah pelatihan.

$\mathrm{H} 2$ : Motivasi berpengaruh terhadap produktivitas kerja pada bank umum syariah Palembang Hasil penelitian ini sesuai dengan penelitian sebelumnya oleh (Assagaf \& Dotulong, 2015). Peranan manusia dalam mencapai tujuan tersebut sangat penting dalam pencapaian tujuan organisasi. Untuk menggerakkan pegawai agar sesuai dengan yang dikehendaki organisasi, maka haruslah dipahami motivasi dari pegawai bekerja pada suatu organisasi, karena motivasi inilah yang menentukan perilaku pegawai untuk bekerja. Dalam islam sumber motivasi itu bersumber dari hati dimana seseorang mengetahui bagaimana dia harus mendekatkan diri kepada Allah SWT baik dalam ibadah mahdah (ritual) ataupun dalam bekerja. Adapun hadist yang berhubungan dengan motivasi kerja salah satunya adalah.

"Sesungguhnya Allah suka kepada hamba yang berkarya dan terampil profesional atau ahli. Barang siapa bersusah-payah mencari nafkah untuk 
Pengaruh Pelatihan dan Motivasi terhadap Kinerja Karyawan dengan Produktivitas

Kerja Sebagai Variabel Intervening pada Bank Umum Syariah Di Kota Palembang

keluarganya maka dia serupa dengan seorang mujahid di jalan Allah Azza wajalla". (HR. Ahmad).

H3: Pelatihan berpengaruh terhadap kinerja karyawan pada bank Umum syariah di Kota Palembang Penelitian ini sejalan dengan penelitian sebelumnya oleh Renaldy Massie, Brnhard Tewal dan Greis Sendow (2015). pelatihan merupakan kegiatan yang direncanakan, sistematis dan menghasilkan tingkat peningkatan keterampilan, pengetahuan dan kompetensi yang diperlukan untuk melakukan pekerjaan secara efektif. Pelatihan tidak hanya mengembangkan mental karyawan tetapi juga mempersiapkan mereka untuk membuat lebih baik kesehatan mereka agar dengan pikiran yang aktif dan pemikiran yang lebih produktif bagi organisasi. Wahyu pertama yang diturunkan kepada Nabi Muhammad adalah surat Al Alaq ayat 1-5: (1) Bacalah dengan (menyebut) nama Tuhanmu Yang menciptakan; (2) Dia telah menciptakan manusia dari segumpal darah;.(3) Bacalah, dan Tuhanmulah Yang Maha Pemurah; (4) Yang mengajar (manusia) dengan perantaran kalam; (5) Dia mengajar kepada manusia apa yang tidak diketahuinya. Inti dari ayat itu umat seharusnya terpanggil untuk terus menerus meningkatkan mutu sumberdaya (SDM) manusianya melalui proses pembelajaran bersinambung.

H4: Motivasi berpengaruh terhadap Kinerja Karyawan pada bank umum syariah di Kota Palembang Penelitian ini sejalan dengan penelitian sebelumnya oleh (Antaka, 2018). Motivasi sebagai suatu proses yang menunjukan intensitas individu, arahan dan ketekunan dalam usahanya ke arah pencapaian tujuan. Motivasi merupakan sesuatu yang menimbulkan semangat dorongan kerja atau pemberian daya penggerak yaang menciptakan gairahan kinerja karyawan pada bank umum syariah di kota Palembang, agar mereka mau bekerja sama, bekerja efektif, dan teritegrasi dengan segala daya upayanya untuk mencapai kepuasaan.

H5: Produktivitas berpengauh terhadap Kinerja Karyawan pada Bank Umum Syariah di Kota Palembang Hasil penelitian ini Sejalan dengan penelitian sebelumnya oleh (Rohmat, Makmun, \& Hasan, 2014). Kinerja yang baik sangat penting dalam suatu perusahaan untuk mencapai tujuan sehingga berbagai usaha harus dilakukan perusahaan untuk meningkatkannya. Kinerja dapat diartikan sebagai hasil pencapaian dari tujuan yang telah direncanakan. Seperti dalam Firman Allah QS. At-taubah Ayat 105 yang artinya: Dan Katakanlah:” Bekerjalah kamu, Maka Allah dan rasul-Nya serta orang-orang mukmin akan melihat pekerjaanmu itu, dan kamu akan dikembalikan kepada Allah yang mengetahui akan yang ghaib dan yang nyata, lalu diberitakan-Nya kepada kamu apa yang telah kamu kerjakan. Merupakan suatu syarat untuk tercapainya tujuan sehingga perlu diupayakan agar kinerja karyawan dapat ditingkatkan. Hal ini sesuai dengan asumsi teoritis, yang menyatakan produktivitas merupakan bagian yang tidak boleh dilupakan dalam penyusunan strategi bisnis atau strategi manajemen yang mencakup bidang produksi, pemasaran, keuangan dan bidang 
bidang lainnya, dimana tiap - tiap bidang tersebut tidak lepas dari tenaga kerja sebagai pelaksananya.

H6: pelatihan terhadap kinerja karyawan melalui produktivitas kerja pada bank umum syariah di Kota Palembang tidak terdapat pengaruh. Hasil penelitian ini sejalan dengan penelitian Pungky Sambur, (Polla, Mananeke, \& Taroreh, 2018) produktivitas kerja tidak dapat memediasi hubungan antara pelatihan terhadap kinerja karyawan. Hal ini bertolak belakang dengan asumsi teoritis yang menyatakan bahwa pelatihan merupakan salah satu faktor determinan untuk meningkatkan kinerja karyawan dan produktivitas kerja dalam perusahaan, dan Produktivitas itu sendiri pada dasarnya merupakan sikap mental yang selalu mempunyai pandangan bahwa kehidupan hari ini harus lebih baik dari hari kemarin dan hari esok harus lebih baik dari hari ini. Dalam hal ini diindikasih bahwa sasaran dalam memberikan pelatihan bukan pada orang yang tepat. Oleh karena itu sebaiknya pihak perusahaan lebih memperhatikan setiap sasaran kedepan.

H7: Motivasi Terhadap Kinerja Karyawan Melalui Produktivitas Kerjaa Pada Bank Umum Syariah di Kota Palembang Berpengaruh Secara Positif Dan Signifikan Hasil penelitian ini sejalan dengan penelitian seblumnya oleh (Azas, Ramadhoni, \& Tamsah, 2019) produktivitas mampu memediasi hubungan antara motivasi terhadap Kinerja karyawan. Produktivitas harus menjadi bagian yang tidak boleh dilupakan dalam dalam menjalankan tujuan-tujuan perusahaan, Ayat berikut menjelaskan bahwa apapun yang kita kerjakan di dunia sudah tercatat dalam kitabnya. Sehingga pentingnya penghayatan terhadap makna-makna yang terkadung dalam al-Quran. Dengan penghayatan tersebut diharapkan tumbuh sikap yang konsekuen dalam prilaku yang selalu megarah pada cara kerja yang efesien dan memanfaatkan waktu dengan sebaik-baiknya dalam bekerja. Sikap seperti ini merupakan modal dasar yang selalu berorientasi pada nilai-nilai produktif.

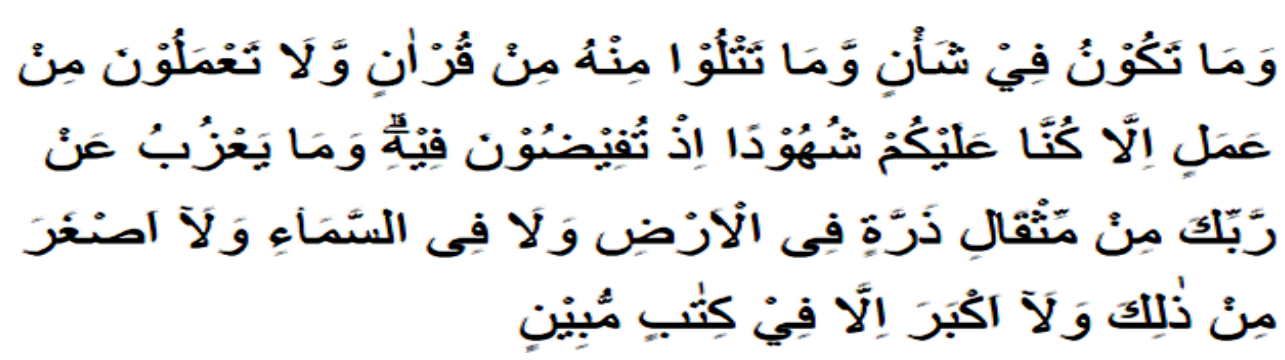

"Kamu tidak berada dalam suatu Keadaan dan tidak membaca suatu ayat dari Al Quran dan kamu tidak mengerjakan suatu pekerjaan, melainkan Kami menjadi saksi atasmu di waktu kamu melakukannya. tidak luput dari pengetahuan Tuhanmu biarpun sebesar zarrah (atom) di bumi ataupun di langit. tidak ada yang lebih kecil dan tidak (pula) yang lebih besar dari itu, melainkan (semua tercatat) dalam kitab yang nyata (Lauh Mahfuzh)." 
Pengaruh Pelatihan dan Motivasi terhadap Kinerja Karyawan dengan Produktivitas

Kerja Sebagai Variabel Intervening pada Bank Umum Syariah Di Kota Palembang

\section{Kesimpulan}

Berdasarkan hasil penelitian variabel pelatihan dan motivasi sangat berkontribusi secara positif terhadap pencapaian kinerja karyawan pada bank umum syariah di kota palembang, dan untuk hubungan antara variabel pelatihan tidak dapat berkontibusi secara signifikan terhadap produktivitas kerja pada bank umum syariah di di kota Palembang. Variabel yang paling berkontibusi secara positif terhadap kinerja karyawan dengan dimediasi variabel produktivitas kerja dalam penelitian ini ialah variabel motivasi. dan hal tersebut telah dituangkan dalam simpulan penelitian dengan disertakan hasil statistik hubungan antar variable sesuai dengan hipotesis. Sebagai tindak lanjut bersama ini penulis menyampaikan beberapa saran untuk dapat dijadikan masukan bagi lembaga dalam rangka meningkatkan efektifitas kinerja karyawan. Adapun saran tersebut ialah, memberikan pelatihan pada orang yang tepat, pihak perusahaan harus lebih memperhatikan untuk meningkatkan dan memberikan pelatihan kerja yang lebih baik dan lebih memperhatikan setiap sasaran kedepan siapa pelatihan akan diberikan sehingga nantinya apa yang didapatkan dalam pelatihan bisa menerapkan sesuai apa yang harus dikerjakan. Dengan memilih sasaran yang tepat dalam memberikan pelatihan akan sangat membatu perusahaan dalam meningkatkan kinerja karyawan dan produktivitas kerja perusahaan karena pelatihan merupakan serangkaian aktivitas dalam meningkatkan keahlian dan pengetahuan secara sistematis sehingga mampu memiliki kinerja yang professional dibidangnya. 


\section{BIBLIOGRAFI}

Antaka, Pebri Fitri. (2018). Pengaruh Motivasi Kerja dan Beban Kerja terhadap Kinerja Karyawan Dipo Lokomotif dan Kereta PT. Kereta Api Indonesia (PERSERO) Daerah Operasi 6 Yogyakarta. Jurnal Manajemen Bisnis Indonesia (JMBI), 7(6), 647-654. Google Scholar

Assagaf, Shannon Cecilia Y., \& Dotulong, Lucky O. H. (2015). Pengaruh Disiplin, motivasi dan semangat kerja terhadap produktivitas kerja pegawai dinas pendapatan daerah kota manado. Jurnal EMBA: Jurnal Riset Ekonomi, Manajemen, Bisnis Dan Akuntansi, 3(2). Google Scholar

Azas, Andi Imran, Ramadhoni, Buyung, \& Tamsah, Hasmin. (2019). Pengaruh Motivasi Kerja, Kompensasi Dan Pelatihan Terhadap Kinerja Pegawai Pada Rektorat Uin Alauddin Makassar. YUME: Journal of Management, 2(1). Google Scholar

Belisle, Annie, Gautier, Marie Sophie, Ghozali, Farida, Plantier, Françoise, \& Wechsler, Janine. (2005). A collision tumor involving basal cell carcinoma and lentigo maligna melanoma. The American Journal of Dermatopathology, 27(4), 319-321. Google Scholar

Ghozali, Imam, \& Latan, Hengky. (2015). Partial Least Squares. Konsep, Teknik Dan Aplikasi Menggunakan Program SmartPLS, 3.

Hair, Joseph F., Black, William C., Babin, Barry J., Anderson, Rolph E., \& Tatham, Ronald L. (2006). Multivariate data analysis (Vol. 6): Pearson Prentice Hall Upper Saddle River. NJ. Google Scholar

Haryono, Slamet. (2017). Struktur kepemilikan dalam bingkai teori keagenan. Jurnal Akuntansi Dan Bisnis, 5(1). Google Scholar

Polla, Febriano Clinton, Mananeke, Lisbeth, \& Taroreh, Rita N. (2018). Analisis pengaruh harga, promosi, lokasi dan kualitas pelayanan terhadap keputusan pembelian pada PT. Indomaret Manado Unit Jalan Sea. Jurnal EMBA: Jurnal Riset Ekonomi, Manajemen, Bisnis Dan Akuntansi, 6(4). Google Scholar

Rohmat, Asep Saepul, Makmun, Dadang, \& Hasan, Irsan. (2014). Gastric pH Comparison Between Mild and Severe Cirrhotic Portal Hypertensive Gastropathy. The Indonesian Journal of Gastroenterology, Hepatology, and Digestive Endoscopy, 15(2), 78-82. Google Scholar

Sambur, Pungky, Mananeke, Lisbeth, \& Taroreh, Rita N. (2018). Pengaruh Pelatihan Kerja Dan Penempatan Kerja Terhadap Produktivitas Kerja Dinas Kebudayaan Daerah Sulawesi Utara. Jurnal EMBA: Jurnal Riset Ekonomi, Manajemen, Bisnis Dan Akuntansi, 6(1). Google Scholar

Tenenhaus, Michel. (2004). A PLS approach to multiple table analysis. In 
Pengaruh Pelatihan dan Motivasi terhadap Kinerja Karyawan dengan Produktivitas Kerja Sebagai Variabel Intervening pada Bank Umum Syariah Di Kota Palembang

Classification, Clustering, and Data Mining Applications (pp. 607-620). Springer. Google Scholar

Yamin, Sofyan, \& Kurniawan, Heri. (2011). Generasi Baru mengolah data Penelitian dengan PLS Path Modeling. Jakarta, Salemba Infotek. Google Scholar

\section{Copyright holder:}

Muhammad Ilham Qolbi, Maya Panorama dan Peny Cahaya Azwari (2021)

First publication right:

Journal Syntax Literate

This article is licensed under:

(c) ${ }_{\mathrm{EY}} \ominus$ 